\title{
New Interaction Tools for Preserving an Old Language
}

\author{
Beryl Plimmer, ${ }^{1,2}$, Liang He ${ }^{2,3}$, Tariq Zaman ${ }^{4}$, Kasun Karunanayaka², Alvin W. Yeo \\ Garen Jengan, Rachel Blagojevic, ${ }^{5}$ Ellen Yi-Luen Do ${ }^{2}$ \\ University of Auckland ${ }^{1}$, CUTE Center, National University of Singapore ${ }^{2}$, Carnegie Mellon \\ University $^{3}$, ISITI, Universiti Malaysia Sarawak, Malaysia ${ }^{4}$, Massey University, New Zealand ${ }^{5}$ \\ beryl@cs.auckland.ac.nz, lianghe@andrew.cmu.edu, zamantariq@gmail.com, \\ kasun@mixedrealitylab.org, alvin@isiti.unimas.my, susilanatasya@gmail.com, \\ R.V.Blagojevic@massey.ac.nz, ellendo@acm.org
}
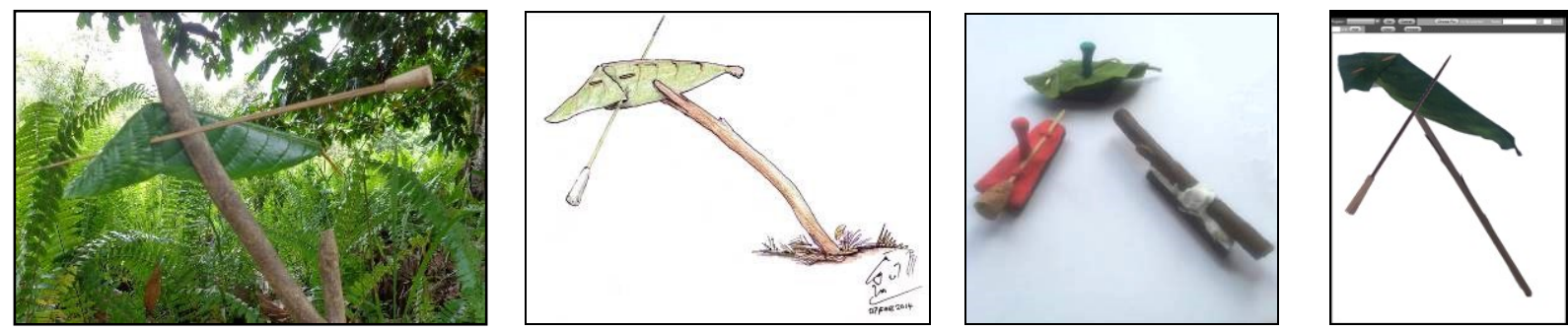

Figure 1 Oroo' sentence "I have left a hunted boar (or part of it) for you in this direction" a) in jungle, b) sketched by a Penan artist, c) tangibles of symbols d) made in application with tangibles

\begin{abstract}
The Penan people of Malaysian Borneo were traditionally nomads of the rainforest. They would leave messages in the jungle for each other by shaping natural objects into language tokens and arranging these symbols in specific ways - much like words in a sentence. With settlement, the language is being lost as it is not being used by the younger generation. We report here, a tangible system designed to help the Penans preserve their unique object writing language. The key features of the system are that: the tangibles are made of real objects; it works in the wild; and new tangibles can be fabricated and added to the system by the users. Our evaluations show that the system is engaging and encourages intergenerational knowledge transfer, thus has the potential to help preserve this language.
\end{abstract}

\section{Author Keywords}

TUI; fabrication; capacitive tangibles; preservation of language

\section{ACM Classification Keywords}

H.5.2 [Information Interfaces and Presentation]: User Interfaces - Interaction styles

Permission to make digital or hard copies of all or part of this work for personal or classroom use is granted without fee provided that copies are not made or distributed for profit or commercial advantage and that copies bear this notice and the full citation on the first page. Copyrights for components of this work owned by others than ACM must be honored. Abstracting with credit is permitted. To copy otherwise, or republish, to post on servers or to redistribute to lists, requires prior specific permission and/or a fee. Request permissions from Permissions@acm.org.

CHI 2015, April 18 - 23 2015, Seoul, Republic of Korea

Copyright is held by the owner/author(s). Publication rights licensed to ACM. ACM 978-1-4503-3145-6/15/04 ..\$15.00

http://dx.doi.org/10.1145/2702123.2702339

\section{INTRODUCTION}

The Penan village of Long Lamai is nestled in the rainforests of Malaysian Borneo about $300 \mathrm{~km}$ from the coast close to the Indonesian border. It is an example of a tribe that has successfully transitioned from a nomadic lifestyle to a self-reliant settled community. The village consists of about 100 families, each with their own home and gardens. Access to the village is by river: the villagers' small outboard powered boats ply the river from Long Banga, the local airstrip and hub, to Long Lamai in about 90 minutes. The village has a primary school, church, micro-hydro dam, gravity-fed running water and a telecentre. The telecentre, developed in liaison with Universiti Malaysia Sarawak, provides Internet access via VSAT (a satellite communications systems) and WiFi that is accessible in the centre of the village. A $3 \mathrm{G}$ mobile tower was set up recently. Many of the villagers have laptops and mobile phones.

The community settled in Long Lamai in the mid-1950's. This has brought many advantages, such as education for all children and better access to medical care. However, it has also resulted in the loss of traditional knowledge, in particular, Oroo', the focus of this project. Oroo' is the object writing [14 p25] language used by earlier generations to leave messages for each other in the jungle. The elders realized that Oroo' will be lost if they do not find ways to preserve and teach it to the younger generations.

Research engagement with the community has shown that only those over 60 who lived the nomadic life during their youth have a full command of the language [37]. This means that only a few individuals hold the key to retaining this language which is an integral part of their culture. 